\title{
Biodiesel Production from Selected Microalgae Strains and Determination of its Properties and Combustion Specific Characteristics
}

\author{
N. Kokkinos ${ }^{1,2, *}$, A. Lazaridou ${ }^{1}$, N. Stamatis ${ }^{3}$, S. Orfanidis ${ }^{3}$, A. Ch. Mitropoulos ${ }^{1,2}$, A. \\ Christoforidis ${ }^{1,2}$ and N. Nikolaou ${ }^{1}$ \\ ${ }^{1}$ Eastern Macedonia and Thrace Institute of Technology, Faculty of Engineering, \\ Department of Petroleum \& Mechanical Engineering, St. Lucas, 65404 Kavala, Greece \\ ${ }^{2}$ Hephaestus Advanced Research Laboratory, Division of Petroleum Engineering, Ag. Lucas, 65404 Kavala, Greece \\ ${ }^{3}$ Hellenic Agricultural Organization-DEMETER, Fisheries Research Institute, 64007 Nea Peramos, Kavala, Greece
}

Received 25 October 2015; Accepted 7 November 2015

\begin{abstract}
Biofuels are gaining importance as significant substitutes for the depleting fossil fuels. Recent focus is on microalgae as the third generation feedstock. In the present research work, two indigenous fresh water and two marine Chlorophyte strains have been cultivated successfully under laboratory conditions using commercial fertilizer (Nutrileaf 30-10-10, initial concentration $=70 \mathrm{~g} / \mathrm{m}^{3}$ ) as nutrient source. Gas chromatographic analysis data showed that microalgae biodiesel obtained from Chlorophyte strains biomass were composed of fatty acid methyl esters. The produced microalgae biodiesel achieved a range of $2.2-10.6 \%$ total lipid content and an unsaturated FAME content between 49 mol\% and 59 $\mathrm{mol} \%$. The iodine value, the cetane number, the cold filter plugging point, the oxidative stability as well as combustion specific characteristics of the final biodiesels were determined based on the compositions of the four microalgae strains. The calculated biodiesel properties compared then with the corresponding properties of biodiesel from known vegetable oils, from other algae strains and with the specifications in the EU (EN 14214) and US (ASTM D6751) standards. The derived biodiesels from indigenous Chlorophyte algae were significantly comparable in quality with other biodiesels.
\end{abstract}

Keywords: Microalgae, chlorophytes, FAME compositions, empirical models, biodiesel properties

\section{Introduction}

The demand for alternative fuels has increased in the past several years. Nowadays, biofuels play a leading role in the substitution of the depleting fossil fuels $[1,2]$. Biofuels derived from biological materials, and this is the main differentiation from other non-fossil fuel energy sources (e.g. wind and wave energy). Biological-based fuels can be solid (e.g. wastes), gaseous (e.g. methane, dymethyl ether, hydrogen) and liquid (e.g. biobutanol, biodiesel). The biggest advantage of biofuels is the environmentally friendliness that they have over fossil fuels. Particularly, biodiesel (from the Greek word Bios: life + diesel from Rudolf Diesel) is a sustainable and renewable fuel, as a result of solar energy conversion into chemical energy. It is biodegradable (degrades about four times faster than petrodiesel) [3], non-toxic and basically free of sulfur and aromatics. The emissions produced by burning of biodiesel are less reactive with sunlight than those produced by burning gasoline; it emits generally less carbon dioxide, carbon monoxide, particulate matter, hydrocarbons, smoke, noxious fumes and odors than mineral diesel fuel. Furthermore, comparing biodiesel with petrodiesel, the former shows higher combustion efficiency, higher cetane number, higher flash point, and inherent luobricity (about $66 \%$ better than petrodiesel) [3-5].

* E-mail address: nikokkinos@mwpc.gr ISSN: 1791-2377 @ 2015 Kavala Institute of Technology. All rights reserved.
On the other hand, biodiesel exhibits higher viscosity, lower energy content, higher cloud point, higher pour point, decreased oxidative stability and slightly increased nitrogen oxide (NOx) emissions compared with petroleum-based diesel fuel [3]. In addition, it is worthy of remark that the first produced biodiesel derived from edible oil seed crops (first generation feedstocks) is lurking a serious risk of disturbing the overall worldwide balance of food reserves and safety. The second generation feedstocks for biodiesel production are obtained from non-edible oil seed crops, waste cooking oil, animal fats, etc. However, these feedstocks are not sufficient to cover the present energy needs. Therefore, recent worldwide attention is on algae, mainly microalgae, as the third generation feedstock [6].

Microalgae are microscopic photosynthetic organisms that are found in both marine and freshwater environments. Bacillariophyceae (diatoms), Chlorophyceae (green algae), and Chrysophyceae (golden algae) are the three most important classes of microalgae in terms of abundance. They do not compete for land; instead they can grow in salty (sea), brackish (lagoons) and fresh (lakes) water. These photosynthetic organisms sequester the atmospheric $\mathrm{CO}_{2}$ and release oxygen. In spite of the fact that the photosynthetic mechanism of microalgae is similar to landbased plants, the primitive simple cellular structure of microalgae, their large surface-to-volume-body ratio and their efficient access to water, $\mathrm{CO}_{2}$, and other nutrients provide them with the ability to grow much faster than terrestrial crops by converting more efficient solar energy into biomass $[7,8]$. The fact that microalgae can complete an entire growing cycle every few days offer them the potential to produce more oil per acre than any other feedstock being 
used to make biodiesel [9]. According to Becker (1994) [10], there are algae types that are comprised of up to $40 \%$ of their overall mass by fatty acids. The producing algal fuels can give 30 to 100 times more energy per hectare compared to biofuels produced from terrestrial crops [9].

During the past few years, we have been thoroughly examining the partial hydrogenation of polyunsaturated methyl esters of sunflower oil to monounsaturated methyl esters in order to improve the final quality of biodiesel [11]. Then, we studied the optimisation of cotton seed biodiesel quality, through the modification of its fatty acid methyl ester (FAME) composition and those hydrogenation conditions that could supply it [12]. In the present research work, two indigenous fresh water and two marine Chlorophyte microalgae strains have been cultivated successfully under laboratory conditions. The extracted oil from the algal biomass was transesterificated to biodiesel. Various biodiesel properties and combustion characteristics were determined based on existing empirical models of biodiesel properties.

\section{Experimental details}

\subsection{Materials}

Hydrogen, nitrogen, argon, zero air and helium 5.0N were purchased from Linde Hellas and Axarlis. $\mathrm{NaOH}, \mathrm{CH}_{3} \mathrm{OH}$, $\mathrm{HCl}(4 \mathrm{M}), \mathrm{BF}_{3}$, iso-octane and petroleum ether were purchased from Sigma-Aldrich. $\mathrm{Na}_{2} \mathrm{SO}_{4}$ was used for drying and was obtained from Panreac.

\subsection{Analytical Method}

The method of gas chromatography with flame ionization detector (FID) was used for qualitative and quantitative analysis of the fatty acid methyl esters. Hewlett Packard 5890-Series II GC/FID equipped with a BPX 70 capillary column (50 m x $0.22 \mathrm{~mm}$ I.D. x $0.25 \mu \mathrm{m}$ film thickness) of SGE Analytical Science (Trajan) was used for FAME analysis. Column temperature was kept initially constant at $177{ }^{\circ} \mathrm{C}$ for $18 \mathrm{~min}$. Then, it was raised at $210{ }^{\circ} \mathrm{C}$ at a rate of $2.3{ }^{\circ} \mathrm{C} / \mathrm{min}$ and remained there for $23 \mathrm{~min}$. The temperature of the split injector was $200{ }^{\circ} \mathrm{C}$ and the temperature of the detector was $250{ }^{\circ} \mathrm{C}$. The split ratio was $1: 60$ and the injected volume was $2 \mu \mathrm{L}$. Helium and nitrogen at 36 $\mathrm{mL} / \mathrm{min}$ were used as carrier gas and make up gas, respectively. The flow rates of hydrogen and zero air were $30 \mathrm{~mL} / \mathrm{min}$ and $330 \mathrm{~mL} / \mathrm{min}$, respectively. Solutions of standards compounds were used for peak identification.

\subsection{Typical procedure of algal biodiesel production}

Figure 1 illustrates the process flow diagram of a typical algal biodiesel production starting from the cultivation of Chlorophyte strains till the prediction of the final biodiesel properties. The whole work was carried out in three well equipped laboratories:

i) The Fisheries Research Institute of the Hellenic Agricultural OrganizationDEMETER with expertise in eco-physiology, land-based algae cultivation and chemical analysis.

ii) The Biofuels Laboratory of the Department of Petroleum and Mechanical Engineering at Eastern Macedonia and Thrace Institute of Technology specialised in biofuels production, analysis, catalysis and applications. iii)

The Chemical Process Modelling and Simulations Laboratory of the Department of Petroleum and Mechanical Engineering at Eastern Macedonia and Thrace Institute of Technology specialised in scientific modelling and simulations of process engineering, where the prediction of the final biodiesel properties occurred.

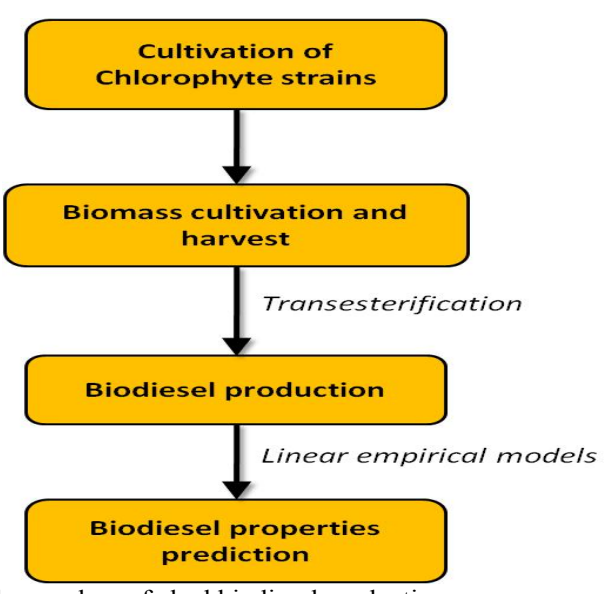

Fig. 1. Typical procedure of algal biodiesel production.

In the beginning [13-15], two indigenous fresh water (ChlorF1, ChlorF2) and two marine (ChlorM1, ChlorM2) Chlorophyte microalgae strains from Northern Greece have been selected and cultivated successfully under laboratory conditions (Figure 2). Commercial fertilizer (Nutrileaf 30$10-10$, initial concentration $\left.=70 \mathrm{~g} / \mathrm{m}^{3}\right)$ was used as nutrient source. Land-based facilities (Figure 3 ) at the greenhouse of Fisheries Research Institute were used for the mass cultivation and harvest. The cultivation took place during spring to autumn. Subsequently, the samples were dried in a Christ freeze dryer and the algal biomass was prepared for oil extraction. Lipids were extracted from the homogenized fresh edible portion by the method of Bligh and Dyer (1959) [16] and were further prepared for fatty acid analysis according to the procedure of Kates (1972) [17]. Methyl esters were prepared by saponification with $0.5 \mathrm{~N} \mathrm{NaOH}$ and methylation with $14 \%$ boron trifluoride-methanol [18].

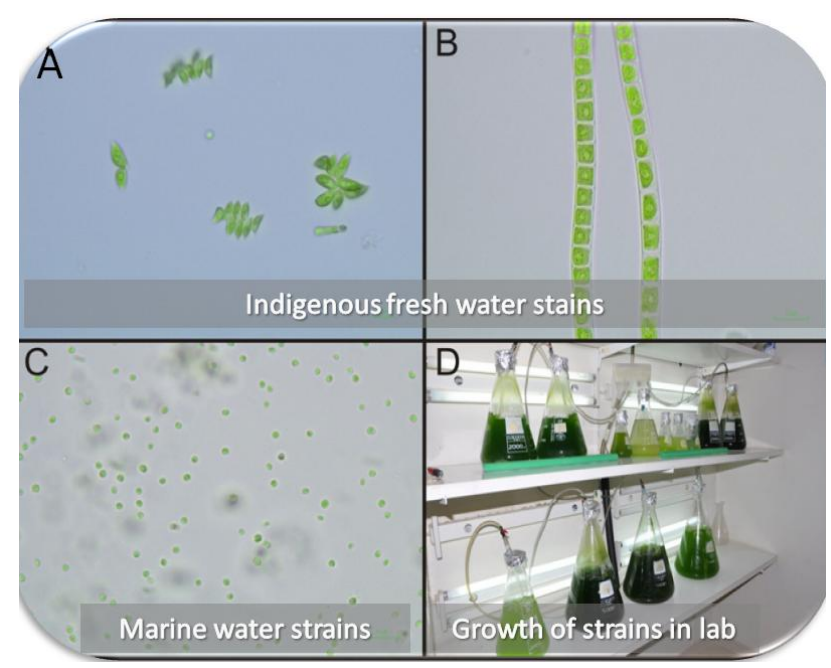

Fig. 2. Chlorophyte strains cultivated under laboratory conditions using commercial fertilizer (Nutrileaf 30-10-10. initial concentration=70 $\mathrm{g} / \mathrm{m}^{3}$ ) as nutrient source: A. B) indigenous fresh water stains. C) a marine water strain of Chlorella. D) growth of strains under laboratory conditions. 


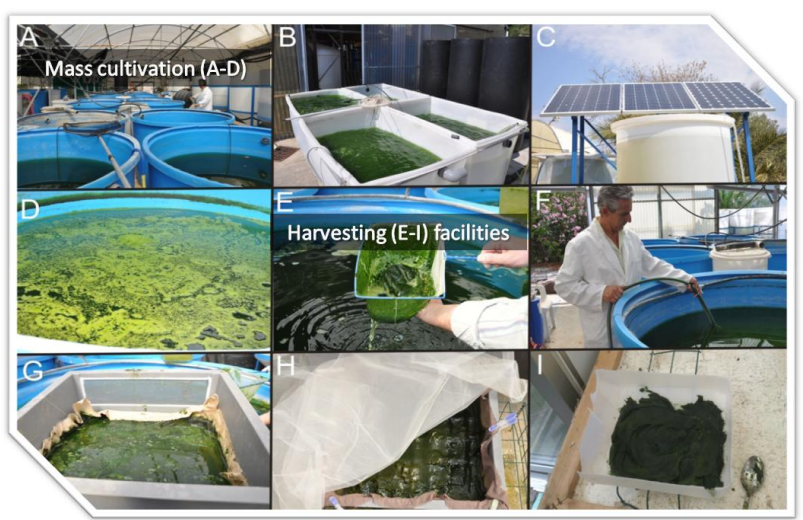

Fig. 3. Mass cultivation (A-D) and harvesting (E-I) facilities of indigenous fresh water Chlorophyte strains at the greenhouse of Fisheries Research Institute, Greece.

\section{Results and discussion}

The produced biodiesel from the microalgae biomass achieved an unsaturated FAME content between $49 \mathrm{~mol} \%$ and $59 \mathrm{~mol} \%$ and a range of $2.2-10.6 \%$ total lipid content. For the calculation of the total lipid content, approximately $5 \mathrm{~g}$ of the sample was mixed with $5 \mathrm{~g}$ celite and $100 \mathrm{~mL}$ hydrochloric acid (4 M) and hydrolysed (Büchi Hydrolysis Unit B-411) at $100{ }^{\circ} \mathrm{C}$, for 30 minutes. Then, the sample was dried in a common microwave oven and extracted via an automated Sohxlet apparatus with petroleum benzin 40-60 (Büchi Extraction System B-811). Right after the solvent evaporation, the beakers were weighted and the total lipid content was calculated according to Equation 1:

$\%$ Fat $=\left(\frac{\left(B_{1}-B_{2}\right)}{\text { Sample Weight }}\right) \times 100$

Where:

$\mathrm{B}_{1}$ : Weight of the beaker with the sample

$\mathrm{B}_{2}$ : Weight of the weighted beaker without the sample

Gas chromatographic analysis data revealed that algal biodiesels obtained from Chlorophyte biomass were composed of fatty acid methyl esters (Figure 4). The compositions of the produced biodiesels by the four microalgae strains, two indigenous fresh water (ChlorF1, ChlorF2) and two marine (ChlorM1, ChlorM2) Chlorophyte microalgae strains, are summarised in Table 1. Also, it can be noticed that biodiesels derived from the specific marine Chlorophyte microalgae strains do not contain C22:0.

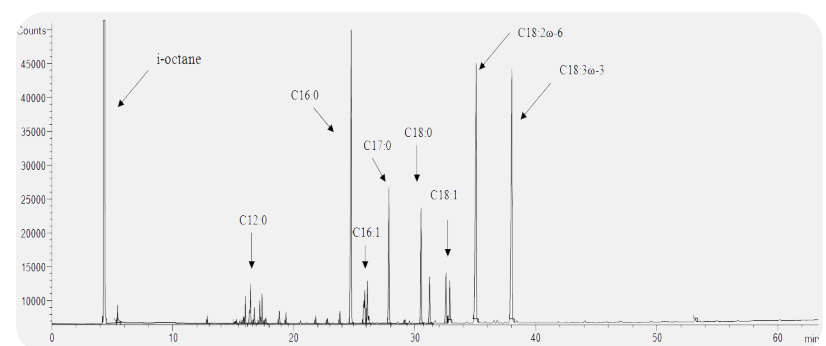

Fig. 4. Typical GC chromatograph of biodiesel from Chlorophyte strains.

Based on the biodiesel compositions derived from microalgae strains (Table 1), the iodine value, the cetane number, the cold filter plugging point and the oxidative stability of the ultimate biodiesels were determined. Most of the literature in the field of empirical modelling and prediction of biodiesel properties employs the generic linear Equation 2. According to Equation 2, the biodiesel (mixture of FAMEs) is regarded as near-ideal solutions of pure FAMEs and its properties can be derived from a simple linear equation of the known specific properties of the individual pure FAMEs.

$P_{\text {Biodiesel }}=\sum_{i=1}^{N} P_{F_{A M E_{i}}} \cdot C_{F A M E_{i}}$

\section{Where:}

$P_{\text {Biodiesel }}$ : Property of biodiesel as a mixture of FAMEs

$P_{F A M E_{i}}$ : Specific property of a pure FAME

$C_{F A M E_{i}}$ : Concentration of a pure FAME in the mixture

Table 1. Composition of biodiesels derived from four Chlorophyte microalgae strains (fresh water: ChlorF1, ChlorF2 and marine: ChlorM1, ChlorM2).

\begin{tabular}{ccccc}
\hline \multicolumn{5}{c}{ Biodiesel composition (wt.\%) } \\
\hline FAME & ChlorF1 & ChlorF2 & ChlorM1 & ChlorM2 \\
\hline C12:0 & 1.85 & 1.25 & 2.17 & 2.70 \\
C16:0 & 38.62 & 22.32 & 26.33 & 23.38 \\
C16:1 & 10.43 & 4.05 & 3.75 & 3.32 \\
C17:0 & 2.49 & 4.70 & 1.97 & 9.38 \\
C18:0 & 5.22 & 8.15 & 11.49 & 8.59 \\
C18:1 & 16.33 & 5.72 & 4.02 & 3.61 \\
C18:2 & 11.89 & 14.75 & 14.87 & 24.92 \\
C18:3 & 12.57 & 36.69 & 35.40 & 24.11 \\
C22:0 & 0.59 & 2.38 & 0.00 & 0.00 \\
\hline
\end{tabular}

3.1 Determination of iodine value and cetane number of algal biodiesel

The iodine value (IV) is a measure of the total unsaturation within a FAME mixture. Particularly, IV expresses the grams of iodine which will react and will finally be added to the double bonds of $100 \mathrm{~g}$ biodiesel. Moreover, the IV indicates the tendency of the oil or fat to polymerize and form engine deposits. Despite unsaturated fatty acid components in FAMEs are required, due to the restriction of FAME solidification, higher degree of unsaturation leads to the unwanted event of FAME polymerization.

The IV was determined by using the widely accepted method of EN 14214 standard (Annex B) [19]. The IVs of the four algal biodiesel were calculated according to Equation 3.

$$
\begin{aligned}
I V_{1}=0.95 \cdot C 16 & : 1 \% w / w+0.86 \cdot C 18 \\
& : 1 \% w / w+1.732 \cdot C 18 \\
& : 2 \% w / w+2.616 \cdot C 18 \\
& : 3 \% w / w+0.785 \cdot C 20 \\
& : 1 \% w / w+0.723 \cdot C 22 \\
& : 1 \% w / w
\end{aligned}
$$

Table 3 revealed that the produced algal biodiesel derived from ChlorF1 surpassed in IV other selected microalgae strains and also Coelastrum [20]. ChlorF2 feedstock offered an IV equal to sunflower feedstock [21]. However, ChlorF2, ChlorM1 and also soybean biodiesels [21] are out of the specifications of EN 14214 (Table 2). 
Table 2. Predicted biodiesel properties comparing with the specifications in the EU and US standards.

\begin{tabular}{|c|c|c|c|c|c|c|c|}
\hline Property & Units & $\begin{array}{l}\text { ASTM } \\
\text { D6751 }\end{array}$ & $\begin{array}{c}\text { EN } \\
14214\end{array}$ & $\begin{array}{c}\text { ChlorF } \\
1\end{array}$ & $\begin{array}{c}\text { ChlorF } \\
2\end{array}$ & $\begin{array}{c}\text { ChlorM } \\
1\end{array}$ & $\begin{array}{c}\text { ChlorM } \\
2\end{array}$ \\
\hline Iodine Value & $\begin{array}{c}\mathrm{gI}_{2} / 100 \mathrm{~g} \\
\mathrm{BD}\end{array}$ & - & $\max .120$ & 78 & 132 & 125 & 112 \\
\hline Cetane Number & - & $\min .47$ & $\min .51$ & 56 & 45 & 46 & 49 \\
\hline CFPP & ${ }^{\circ} \mathrm{C}$ & - & -* & 7 & 15 & 10 & 4 \\
\hline $\begin{array}{l}\text { Oxidative } \\
\text { Stability }\end{array}$ & $\mathrm{h} ; 110^{\circ} \mathrm{C}$ & $\min .3$ & $\min .6$ & 7 & 5 & 5 & 5 \\
\hline
\end{tabular}

* Country specific CFPP (Greece) according to ELOT EN 14214: $+5^{\circ} \mathrm{C} /-5^{\circ} \mathrm{C}$

Table 3. Predicted biodiesel properties comparing with the corresponding properties of biodiesel from known vegetable oils and from other algae strain.

\begin{tabular}{|c|c|c|c|c|c|c|c|c|c|}
\hline \multirow{2}{*}{ Property } & \multirow{2}{*}{ Units } & \multicolumn{2}{|c|}{ Chlor Chlor } & \multirow{2}{*}{$\begin{array}{c}\text { Chlor } \\
\text { M1 }\end{array}$} & \multirow{2}{*}{$\begin{array}{c}\text { Chlor } \\
\text { M2 }\end{array}$} & \multirow{2}{*}{$\begin{array}{r}\text { Coelastru } \\
\mathbf{m}[20] \\
\end{array}$} & \multicolumn{2}{|c|}{ Soybean Sunflower } & \multirow{2}{*}{$\begin{array}{r}\text { Palm[ } \\
21] \\
\end{array}$} \\
\hline & & & & & & & & & \\
\hline Iodine Value & $\begin{array}{l}\mathrm{g} \mathrm{I}_{2} / 100 \\
\mathrm{~g} \mathrm{BD}\end{array}$ & 78 & 132 & 125 & 112 & 88 & 128 & 132 & 57 \\
\hline Cetane & & & & & & & & & \\
\hline Number & - & 56 & 45 & 46 & 49 & 57 & 49 & 50 & 61 \\
\hline CFPP & ${ }^{\circ} \mathrm{C}$ & 7 & 15 & 10 & 4 & -5 & -5 & -3 & 10 \\
\hline $\begin{array}{l}\text { Oxidative } \\
\text { Stability }\end{array}$ & $\mathrm{h} ; 110^{\circ} \mathrm{C}$ & 7 & 5 & 5 & 5 & 4 & 1 & 1 & 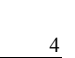 \\
\hline
\end{tabular}

Cetane number $(\mathrm{CN})$ affects a number of engine performance parameters such as combustion, stability, driveability, white smoke, noise, and emissions of $\mathrm{CO}$ and hydrocarbons. The higher the cetane number is, the better it is in its ignition properties (shorter the ignition delay time) and combustion characteristics. The $\mathrm{CN}$ of biodiesel, as a mixture of FAMEs, depends strongly on compound structure. Generally, $\mathrm{CN}$ increases with increasing chain length and degree of saturation. Although FAMEs with higher $\mathrm{CN}$ (such as $\mathrm{CN}$ of methyl stearate ca. 100 and $\mathrm{CN}$ of methyl palmitate ca. 85) are favored for use as biodiesel [22], the increase of $\mathrm{CN}$ means also reduction of biodiesel degree of unsaturation, which leads to the undesirable solidification of FAMEs at higher temperature. Therefore, the upper limit of $\mathrm{CN}$ (65) has been specified in US biodiesel standard (ASTM PS 121-99).

In the current research work, the cetane numbers of the four algal biodiesel were obtained using the empirical method expressed by Equation $4[12,23,24]$. For the determination of saponification number $(\mathrm{SN})$ and iodine value $\left(\mathrm{IV}_{2}\right)$, which this empirical method demands in advance, Equation 5 and Equation 6 were employed, respectively $[12,18,24]$. Apparently, the calculated $\mathrm{CN}$ is negatively correlated to $\mathrm{IV}_{2}$ (Equation 4), due to the fact that $\mathrm{CN}$ decreases with increasing biodiesel degree of unsaturation.

$C N=46.3+\frac{5458}{S N}-0.225 \cdot I V_{2}$

Where:

$C N$ : Cetane number

$S N$ : Saponification number (Equation 5)

$I V_{2}$ : Iodine value (Equation 6)
$S N=\sum \frac{\left(560 \cdot A_{i}\right)}{M_{i}}$

Where:

$S N$ : Saponification number

$A_{i}: \% \mathrm{w} / \mathrm{w}$ of each fatty acid methyl ester

$M_{i}$ : Molecular mass of each fatty acid methyl ester

$I V_{2}=\sum \frac{\left(253.81 \cdot D \cdot A_{i}\right)}{M_{i}}$

Where:

$I V_{2}$ : Iodine value

$D$ : Number of double bonds of each fatty acid methyl ester

$A_{i}: \% \mathrm{w} / \mathrm{w}$ of each fatty acid methyl ester

$M_{i}$ : Molecular mass of each fatty acid methyl ester

According to Table 2, algal biodiesel derived from ChlorF1 strain emerged the best $\mathrm{CN}$ among the four selected Chlorophyte biodiesel feedstocks. In addition, ChlorF1 offered a better $\mathrm{CN}$ to the ultimate biodiesel than biodiesel derived from soybean and sunflower feedstocks [21]; and almost equal $\mathrm{CN}$ to the produced biodiesel from Coelastrum feedstock [20].

3.2 Determination of cold filter plugging point and oxidative stability of algal biodiesel

Low-temperature performance is one of the most important properties of biodiesel and it is mainly specified by the cold filter plugging point (CFPP) of the fuel. The CFPP method is accepted nearly worldwide. In fact, CFPP predicts more effectively the limiting fuel temperatures, where start-up or operability problems may be expected after prolonged exposure, than cloud point $(\mathrm{CP})$ and pour point (PP) could achieve. Particularly, CFPP is the temperature at which a fuel causes a filter to plug as a result of the crystallization of the implicating ester structures. Biodiesel fuels with significant amounts of saturated fatty compounds will display higher CFPPs, due to the fact that saturated fatty compounds have significantly higher melting points than unsaturated fatty compounds [4]. Thus, in a mixture, saturated fatty compounds crystallize at higher temperature than the unsaturated ones. Furthermore, the longer the carbon chains in the biodiesel, the worse the lowtemperature properties [21].

For the determination of the four algal biodiesel CFPPs, the long chain saturated factor LCSF B (Equation 7) of Ramos et al. (2009) [21] was taken into account in conjunction with Equation 8 (with a reported $R^{2}=0.966$ ) [21].

$$
\begin{aligned}
\operatorname{LCSF}(B)=0.1 \cdot & C 16(w t . \%)+0.5 \cdot C 18(w t . \%)+1 \\
\cdot & C 20(w t . \%)+1.5 \cdot C 22(w t . \%)+2 \\
\cdot & C 24(w t . \%)
\end{aligned}
$$

$C F P P=3.1417 \cdot \operatorname{LCSF}(B)-16.477$

Though EN 14214, EN 116, ASTM D-6751 and ASTM D-6371 standards include and describe CFPP measurement method, they do not specify any limit, due to its temperature dependency by the varying climate conditions at different 
countries. According to ELOT EN 14214 (Table 2), in Greece, CFPP is specified as $+5{ }^{\circ} \mathrm{C}$ (in summer) $/-5{ }^{\circ} \mathrm{C}$ (in winter). It can be seen in Table 2 that only ChlorM2 gave a good CFPP value.

Oxidative stability is another important parameter that several standards (such as EN 14214 and ASTM D6751) monitor. Although biodiesel is environmentally compatible, biodiesel fuels are more sensitive to oxidative degradation than fossil diesel fuels. Oxidative stability is strongly affected by the number of FAME molecules having multiple double bonds. Particularly, the oxidative stability decreased with the increase of the contents of polyunsaturated methyl esters. The stability of fatty compounds is influenced, apart from structural features of the compounds themselves, by a variety of other factors such as conditions of storage, temperature, time, presence of oxygen, metal traces and also light [25]. It is worthy of remark that even if appropriate prevention measures are taken, oxidation can be delayed but not completely prevented.

The oxidative stabilities of the current algal biodiesels were determined according to the empirical methodologies of Sarin et al. (2010) [26] and Park et al. (2008) [27]. Almost all oxidative stabilities were within ASTM D6751 specifications, whereas the under comparison soybean and sunflower oils [21] are out of the ASTM specs (Table 2 and Table 3). However, only ChlorF1 is in line with EN 14214 specs. According to Ramos et al. (2009) [21], it is very difficult to meet the minimum limit of Rancimat induction period of $6 \mathrm{~h}$ for biodiesel fuels derived from common raw materials, unless antioxidants are added to the biodiesel.

\subsection{Determination of combustion specific characteristics} of the final algal biodiesels

Equations 9-14 were employed to determine the combustion specific characteristics (CSC) of algal biodiesels. Equation 9 describes the general reaction equation for stoichiometric (complete) combustion of a saturated FAME in oxygen; and Equations 10-12 depict those of unsaturated FAME with one, two and three double bonds (DB), respectively. The oxygen content of FAMEs, the required stoichiometric amount of oxygen in the complete combustion of FAMEs and the produced stoichiometric amount of carbon dioxide in the complete combustion of FAMEs were calculated according to the Equations 9-12, using the molecular weights of FAMEs in Table 4.

$$
\text { Saturated FAMEs: } \begin{aligned}
\mathrm{C}_{n} \mathrm{H}_{2 n+1} \mathrm{COOCH}_{3}+\frac{3 n+4}{2} \mathrm{O}_{2} \\
\rightarrow(n+2) \mathrm{CO}_{2}+(n+2) \mathrm{H}_{2} \mathrm{O}
\end{aligned}
$$

Unsaturated FAMEs (1DB): $\mathrm{C}_{n} \mathrm{H}_{2 n-1} \mathrm{COOCH}_{3}$

$$
\begin{aligned}
& +\frac{3 n+3}{2} \mathrm{O}_{2} \\
& \rightarrow(n+2) \mathrm{CO}_{2}+(n+1) \mathrm{H}_{2} \mathrm{O}
\end{aligned}
$$

Unsaturated FAMEs (2DB): $\mathrm{C}_{n} \mathrm{H}_{2 n-3} \mathrm{COOCH}_{3}$

$$
\begin{aligned}
& +\frac{3 n+2}{2} \mathrm{O}_{2} \\
& \rightarrow(n+2) \mathrm{CO}_{2}+n \mathrm{H}_{2} \mathrm{O}
\end{aligned}
$$

Unsaturated FAMEs (3DB): $\mathrm{C}_{n} \mathrm{H}_{2 n-5} \mathrm{COOCH}_{3}$

$$
\begin{aligned}
& +\frac{3 n+1}{2} \mathrm{O}_{2} \\
& \rightarrow(n+2) \mathrm{CO}_{2}+(n-1) \mathrm{H}_{2} \mathrm{O}
\end{aligned}
$$

Table 4. Molecular weights of fatty acids (FAs) and their

\begin{tabular}{|c|c|c|c|c|c|}
\hline CSC & Units & $\begin{array}{c}\text { ChlorF } \\
1\end{array}$ & $\begin{array}{c}\text { ChlorF } \\
2\end{array}$ & $\begin{array}{c}\text { ChlorM } \\
1\end{array}$ & $\begin{array}{c}\text { ChlorM } \\
2\end{array}$ \\
\hline $\begin{array}{c}\mathrm{O}_{2} \text { in } \\
\text { FAME } \\
\text { Required }\end{array}$ & $\mathrm{g} \mathrm{O}_{2} / 100 \mathrm{~g}$ biodiesel & 11.41 & 11.16 & 11.26 & 11.27 \\
\hline $\begin{array}{l}\mathrm{O}_{2} \text { in } \mathrm{SC}^{*} \\
\text { Produced }\end{array}$ & $\begin{array}{c}\mathrm{g} \mathrm{O}_{2} / 100 \mathrm{~g} \text { biodiesel } \\
\mathrm{g} \mathrm{CO}_{2} / 100 \mathrm{~g}\end{array}$ & 288.96 & 288.18 & 287.91 & 288.31 \\
\hline $\begin{array}{l}\mathrm{CO}_{2} \text { in } \mathrm{SC}^{*} \\
\text { Ignition }\end{array}$ & biodiesel & 279.87 & 281.97 & 281.52 & 281.16 \\
\hline $\begin{array}{l}\text { Delay (ID) } \\
\text { Total }\end{array}$ & ${ }^{\circ} \mathrm{CA}$ & 9 & 10 & 10 & 10 \\
\hline $\begin{array}{l}\text { Combustio } \\
\text { n Duration } \\
\text { (TCD) }\end{array}$ & ${ }^{\circ} \mathrm{CA}$ & 59 & 56 & 57 & 57 \\
\hline
\end{tabular}
methyl esters (FAMEs), where Cn: Number of carbon atoms and DB: Number of double bonds.

\begin{tabular}{ccc}
\hline & \multicolumn{2}{c}{ Molecular Weight } \\
\hline Cn:DB & FA & FAME \\
\hline C12:0 & 200.3233 & 214.3503 \\
C16:0 & 256.4314 & 270.4585 \\
C16:1 & 254.4155 & 268.4425 \\
C17:0 & 270.4585 & 284.4855 \\
C18:0 & 284.4855 & 298.5126 \\
C18:1 & 282.4696 & 296.4966 \\
C18:2 & 280.4536 & 294.4807 \\
C18:3 & 278.4377 & 292.4647 \\
C22:0 & 340.5937 & 354.6207 \\
C24:0 & 368.6478 & 382.6748 \\
\hline
\end{tabular}

Table 5. Combustion specific characteristics (CSC) of biodiesels derived from four Chlorophyte microalgae strains (fresh water: ChlorF1, ChlorF2 and marine: ChlorM1, ChlorM2).

* SC: Stoichiometric (complete) combustion

According to Gopinath et al. (2010) [28], the ignition delay (ID) of the fuel and the total combustion duration (TCD) were determined in terms of degree crank angle, by employing Equation 13 and Equation 14, respectively. Table 5 sums up the examined combustion specific characteristics of algal biodiesel.

$I D=0.0962 \cdot X+4.6837$

$T C D=-0.2806 \cdot X+72.202$

\section{Conclusion}

All selected Chlorophyte microalgae strains from Northern Greece have been cultivated successfully under laboratory conditions. Gas chromatographic analysis data showed that biodiesels obtained from indigenous Chlorophyte algae strains were composed of fatty acid methyl esters. The algal biodiesels achieved a range of 2.2-10.6\% total lipid content and an unsaturated FAME content between $49 \mathrm{~mol} \%$ and 59 mol\%. The properties and combustion specific characteristics of the ultimate biodiesels were determined, based on the compositions of the various substrates. The derived biodiesels from indigenous Chlorophyte algae (above all ChlorF1) were significantly comparable in quality with other biodiesels.

\section{Acknowledgments}

This research has been co-financed by the European Union (European Social Fund - ESF) and Greek national funds 
through the Operational Program "Education and Lifelong Learning" of the National Strategic Reference Framework (NSRF) - Research Funding Program: ARCHIMEDES III.
Investing in knowledge society through the European Social Fund.

\section{References}

1. A.A. Vertès, N. Qureshi, H.P. Blaschek and H. Yukawa, Biomass to Biofuels: Strategies for Global Industries, John Wiley \& Sons Ltd, West Sussex, 2010.

2. A. Demirbas, Progress and recent trends in biodiesel fuels, Energy Conversion and Management, vol. 50, no. 1, 2009, pp. 14-34.

3. A. Demirbas, New liquid biofuels from vegetable oils via catalytic pyrolysis, Energy Education Science Technology, vol. 21, no. 1\&2, 2008, pp. 1-59.

4. G. Knothe, Dependence of biodiesel fuel properties on the structure of fatty acid alkyl esters, Fuel Processing Technology, vol. 86, no. 10, 2005, pp. 1059-1070.

5. H.K. Speidel, R.L. Lightner and I. Ahmed, Biodegradability of new engineered fuels compared to conventional petroleum fuels and alternative fuels in current use, Applied Biochemistry and Biotechnology, vol. 84-86, 2000, pp. 879-897.

6. M.R. Tredici, Photobiology of microalgae mass cultures: understanding the tools for the next green revolution, Biofuels, vol. 1, 2010, pp. 143-162.

7. J. Sheehan, T. Dunahay, J. Benemann and P. Roessler, A Look Back at the U.S. Department of Energy's Aquatic Species Program: Biodiesel from Algae (NREL/TP-580-24190), National Renewable Energy Laboratory, U.S. Department of Energy, Golden, Colorado, 1998.

8. A.S. Carlsson, J.B.v. Beilen, R. Möller and D. Clayton, Micro- and macro-algae: Utility for industrial applications, Outputs from the EPOBIO: Realising the Economic Potential of Sustainable Resources - Bioproducts from Non-food Crops project, D. Bowles, ed., CPL Press, Newbury, UK, 2007.

9. A. Demirbas and M.F. Demirbas, Algae Energy: Algae as a New Source of Biodiesel, Springer-Verlag, London, UK, 2010.

10. E.W. Becker, Microalgae: Biotechnology and Microbiology, Cambridge University Press, New York, 1994.

11. N. Nikolaou, C.E. Papadopoulos, A. Lazaridou, A. Koutsoumba, A. Bouriazos and G. Papadogianakis, Partial hydrogenation of methyl esters of sunflower oil catalyzed by highly active rhodium sulfonated triphenylphosphite complexes, Catalysis Communications, vol. 10, no. 5, 2009, pp. 451-455.

12. C.E. Papadopoulos, A. Lazaridou, A. Koutsoumba, N. Kokkinos, A. Christoforidis and N. Nikolaou, Optimization of cotton seed biodiesel quality (critical properties) through modification of its FAME composition by highly selective homogeneous hydrogenation, Bioresource Technology, vol. 101, no. 6, 2010, pp. $1812-1819$.

13. A. Christoforidis, N. Nikolaou, A. Papadimitriou, N. Stamatis and S. Orfanidis, An integrated process of biodiesel production from indigenous microalgae in Northern Greece: First results, Proc. International Conference on Biofuels for Sustainable Development of Southern Europe (Bio4SuD), 2012.

14. N. Kokkinos, A. Lazaridou, D. Stergiou, A. Papadimitriou, N. Stamatis, S. Orfanidis, A. Mitropoulos, A. Christoforidis and N. Nikolaou, Production, properties and characterization of biodiesel from selected indigenous microalgae strains of Northern Greece, Proc. International Conference on Environment and Renewable Energy (ICERE), 2015.
15. N. Kokkinos, A. Lazaridou, I. Tzovenis, N. Stamatis, S. Orfanidis, A. Mitropoulos, N. Nikolaou and A. Christoforidis, Properties and characterization of biodiesel from selected microalgae strains, Proc. International Conference and Exhibition on Energy, Science \& Technology (EST), 2015.

16. E.G. Bligh and W.J. Dyer, A rapid method of total lipid extraction and purification, Canadian Journal of Biochemistry and Physiology, vol. 37, no. 8, 1959, pp. 911-917.

17. M. Kates, Techniques of Lipidology: Isolation, analysis and identification of lipids, Laboratory Techniques in Biochemistry and Molecular Biology, T.S. Work and E. Work, eds., Elsevier, vol. Volume 3, 1972, p. 267.

18. L.D. Metcalfe, A.A. Schmitz and J.R. Pelka, Rapid Preparation of Fatty Acid Esters from Lipids for Gas Chromatographic Analysis, Analytical Chemistry, vol. 38, no. 3, 1966, pp. 514-515.

19. D. Firestone, AOCS Official Method Cd 1c-85, Official Methods and Recommended Practices of the AOCS, 6th ed., American Oil Chemists' Society, 2013.

20. R. Valdez-Ojeda, M. González-Muñoz, R. Us-Vázquez, J. NarváezZapata, J.C. Chavarria-Hernandez, S. López-Adrián, F. BarahonaPérez, T. Toledano-Thompson, G. Garduño-Solórzano and R.M. Escobedo-Gracia Medrano, Characterization of five fresh water microalgae with potential for biodiesel production, Algal Research, vol. 7, 2015, pp. 33-44.

21. M.J. Ramos, C.M. Fernández, A. Casas, L. Rodríguez and Á. Pérez, Influence of fatty acid composition of raw materials on biodiesel properties, Bioresource Technology, vol. 100, no. 1, 2009, pp. 261268.

22. M.A. Borowitzka and N.R. Moheimani, Algae for biofuels and energy, Springer, Dordrecht, The Netherlands, 2013.

23. K. Krisnangkura, A simple method for estimation of cetane index of vegetable oil methyl esters, Journal of the American Oil Chemists Society, vol. 63, no. 4, 1986, pp. 552-553.

24. M. Mohibbe Azam, A. Waris and N.M. Nahar, Prospects and potential of fatty acid methyl esters of some non-traditional seed oils for use as biodiesel in India, Biomass and Bioenergy, vol. 29, no. 4, 2005, pp. 293-302.

25. D. Bajpai and V.K. Tyagi, Biodiesel: Source, Production, Composition, Properties and Its Benefits, Journal of Oleo Science, vol. 55 , no. 10,2006 , pp. 487-502.

26. A. Sarin, R. Arora, N.P. Singh, R. Sarin and R.K. Malhotra, Blends of biodiesels synthesized from non-edible and edible oils: Influence on the OS (oxidation stability), Energy, vol. 35, no. 8, 2010, pp. 3449-3453.

27. J.-Y. Park, D.-K. Kim, J.-P. Lee, S.-C. Park, Y.-J. Kim and J.-S. Lee, Blending effects of biodiesels on oxidation stability and low temperature flow properties, Bioresource Technology, vol. 99, no. 5, 2008, pp. 1196-1203.

28. A. Gopinath, S. Puhan and G. Nagarajan, Effect of unsaturated fatty acid esters of biodiesel fuels on combustion, performance and emission characteristics of a DI diesel engine, International Journal of Energy and Environment, vol. 1, no. 3, 2010, pp. 411-430. 